\title{
The impact of mother-to-mother support on optimal breast-feeding: a controlled community intervention trial in peri-urban Guatemala City, Guatemala
}

\author{
Kirk Dearden, ${ }^{1}$ Mekibib Altaye, ${ }^{2}$ Irma de Maza, ${ }^{3}$ Maritza de Oliva, ${ }^{3}$ \\ Maryanne Stone-Jimenez, ${ }^{4}$ Barton R. Burkhalter, ${ }^{5}$ and Ardythe L. Morrow ${ }^{2,4}$
}

ABSTRACT Objective. To assess the impact that a mother-to-mother support program operated by La Leche League Guatemala had on early initiation of breast-feeding and on exclusive breast-feeding in peri-urban Guatemala City, Guatemala.

Materials and Methods. A population census was conducted to identify all mothers of infants $<6$ months of age, and the mothers were then surveyed on their breast-feeding practices, in two program communities and two control communities. Data collection for this follow-up census and survey was carried out between November 2000 and January 2001, one year after a baseline census and survey had been conducted.

Results. At follow-up, 31\% of mothers in the program communities indicated that counselors had advised them about breast-feeding, $21 \%$ said they had received a home visit, and $16 \%$ reported attending a support group. Communitywide rates of early initiation of breast-feeding were significantly higher in program areas than in the control communities, at both baseline and follow-up. However, the change over time in early initiation in program communities was not significantly different from the change in control communities. Communitywide rates of exclusive breast-feeding were similar in program and control sites and did not change significantly from baseline to follow-up. However, of the mothers in the program communities who both received home visits and attended support groups, 45\% of them exclusively breast-fed, compared to $14 \%$ of women in program communities who did not participate in those two activities. In addition, women who were exposed to mother-to-mother support activities during the year following the baseline census and survey were more likely than mothers exposed before that period to exclusively breast-feed. This suggests that the program interventions became more effective over time.

Conclusions. This study does not provide evidence of population impact of La Leche League's intervention after one year of implementation. In peri-urban Guatemala, long-term community-based interventions, in partnership with existing health care systems, may be needed to improve communitywide exclusive breast-feeding rates.

Key words Breast-feeding, infant nutrition, social support, health education, health promotion.

Brigham Young University, Department of Health Science, Provo, Utah, United States of America. Send correspondence to: Kirk Dearden, Department of Health Science, Brigham Young University, 213 Richards Building, Provo, UT 84602, United States of America; telephone: (801) 422-4428; fax: (801) 422-0373; e-mail: kirk_ dearden@byu.edu. (Much of this work was carried out while he was at the Academy for Educational Development, The LINKAGES Project, Washington, D.C., United States of America.)

2 Cincinnati Children's Hospital Medical Center, Cincinnati, Ohio, United States of America.
3 La Leche League Guatemala, Guatemala City, Guatemala.

4 Academy for Educational Development, The LINKAGES Project, Washington, D.C., United States of America.

5 University Research Co., Bethesda, Maryland, United States of America. 
Initiation of breast-feeding in the first hour after birth and exclusive breast-feeding for the first 6 months of life are global public health goals aimed at reducing infant morbidity and mortality. A number of strategies have been used to promote these optimal breast-feeding behaviors, but the relative effectiveness of different strategies is not yet well established. There are few rigorous studies that demonstrate the impact of breast-feeding promotion efforts in developing countries. Many of these studies focus on clinic-based interventions occurring at the time of delivery (1-4). Only a handful of community-based studies have been carried out to demonstrate the impact of breast-feeding support activities; these focus largely on the use of paid staff. Data are lacking on the impact of mother-to-mother support groups, one of the most well-known and widespread strategies for promoting breast-feeding (5). Because these support groups are usually community-based, participatory, and experiential, they have the potential to bring about positive changes in the way mothers feed their infants. These characteristics have also made support groups more difficult to study.

The study described here reports on baseline and follow-up surveys for an intervention trial in two program communities and in two control communities of the impact of the mother-tomother support program of La Leche League Guatemala (LLLG) on early initiation of breast-feeding and on exclusive breast-feeding. The study tests the hypothesis that increased peer support for breast-feeding improves optimal breast-feeding practices at the community level, with the greatest impact among women who directly participate in LLLG's programs. A baseline study of factors affecting early initiation of breast-feeding and exclusive breast-feeding is reported separately in this issue of this journal (6). The baseline study identified infant's place of delivery as the most important determinant of early initiation of breast-feeding, with children born at home or at Ministry of Health (MOH) health centers significantly more likely to initiate breast-feeding early than were children born at private hospitals. The most important determinant of exclusive breast-feeding was place of work: mothers who did not work outside the home were far more likely to exclusively breast-feed. After controlling for infant's age and sex and mother's ethnicity, women who did not work outside the home were 3.2 times as likely to exclusively breastfeed in comparison to women who worked outside the home (95\% confidence interval: 1.6-6.4).

In 1989, La Leche League Guatemala began training unpaid volunteer breast-feeding counselors (known in Spanish as monitoras) in low-income peri-urban areas of Guatemala City, which is the capital and largest city of the country. Funding for breastfeeding counselors was intermittent from 1989 to 1999 , but increased thereafter. The counselors receive training and follow-up from LLLG to carry out breast-feeding promotion and support activities in the communities where they live. Counselors facilitate mother-to-mother support groups; visit women in their homes; contact women informally on buses, in markets, and in other public areas; and refer women to nearby health clinics for lactation management for problems that they (the counselors) are not trained to handle. The major focus of the counselors' work has been to facilitate the motherto-mother support groups through periodic home visits. Mother-to-mother support groups are usually held monthly in mothers' homes or in churches, schools, or other public places. During these meetings, counselors introduce one of four major topics: 1) the advantages of breastfeeding, 2) early breast-feeding, including techniques for breast-feeding, 3) breast-feeding difficulties and how to overcome them, and 4) complementary feeding. To facilitate discussion and learning, the League uses large cloth posters for each topic. During group meetings the counselors provide encouragement to the mothers to breast-feed but support them in their infant-feeding decisions whether or not they choose to breast-feed.
A survey of counselors conducted in January 2000 indicated that breastfeeding counselors were typically middle aged (on average, 41.8 years old) and multiparous (mean number of children $=4.0$ ). Thirty-six percent had completed primary school, and $11 \%$ had completed high school. Fiftyone percent reported having paid employment.

In 1999 The LINKAGES Project provided funding to LLLG to expand recruitment and training, quadrupling the number of active counselors in the two program communities of this study, from 22 to 86 counselors. The LINKAGES Project is funded by the United States Agency for International Development (USAID). Through work with ministries of health, private volunteer organizations, and bilateral and multilateral organizations in Africa, Asia, and Latin America, The LINKAGES Project promotes optimal breast-feeding, related complementary feeding, and maternal nutrition practices. The LINKAGES Project is managed by the Academy for Educational Development (AED). AED is an independent nonprofit organization that is headquartered in Washington, D.C.

In 1999 in the two program communities in Guatemala City there was one breast-feeding counselor for every 10 pregnant women and one counselor for every 15 mothers of children less than 6 months of age. Training of counselors began in November of 1999 and ended one year later. In November 2000, when the follow-up data collection was begun, there was one counselor for every 3 pregnant women and one for every 4 mothers of children less than 6 months of age.

Beginning in 1999 La Leche League Guatemala introduced a number of other changes to its program. LLLG more clearly focused on pregnant women and mothers of children less than 6 months of age, as opposed to all women of reproductive age. For example, counselors increased home visits to pregnant women and invited them to attend mother-to-mother support groups. LLLG intensified efforts to communicate key messages. For instance, counselors spoke to pregnant 
FIGURE 1. Data collection process for program communities and control communities in follow-up period, study of impact of mother-to-mother support on optimal breast-feeding, Guatemala City, Guatemala, 1999-2001

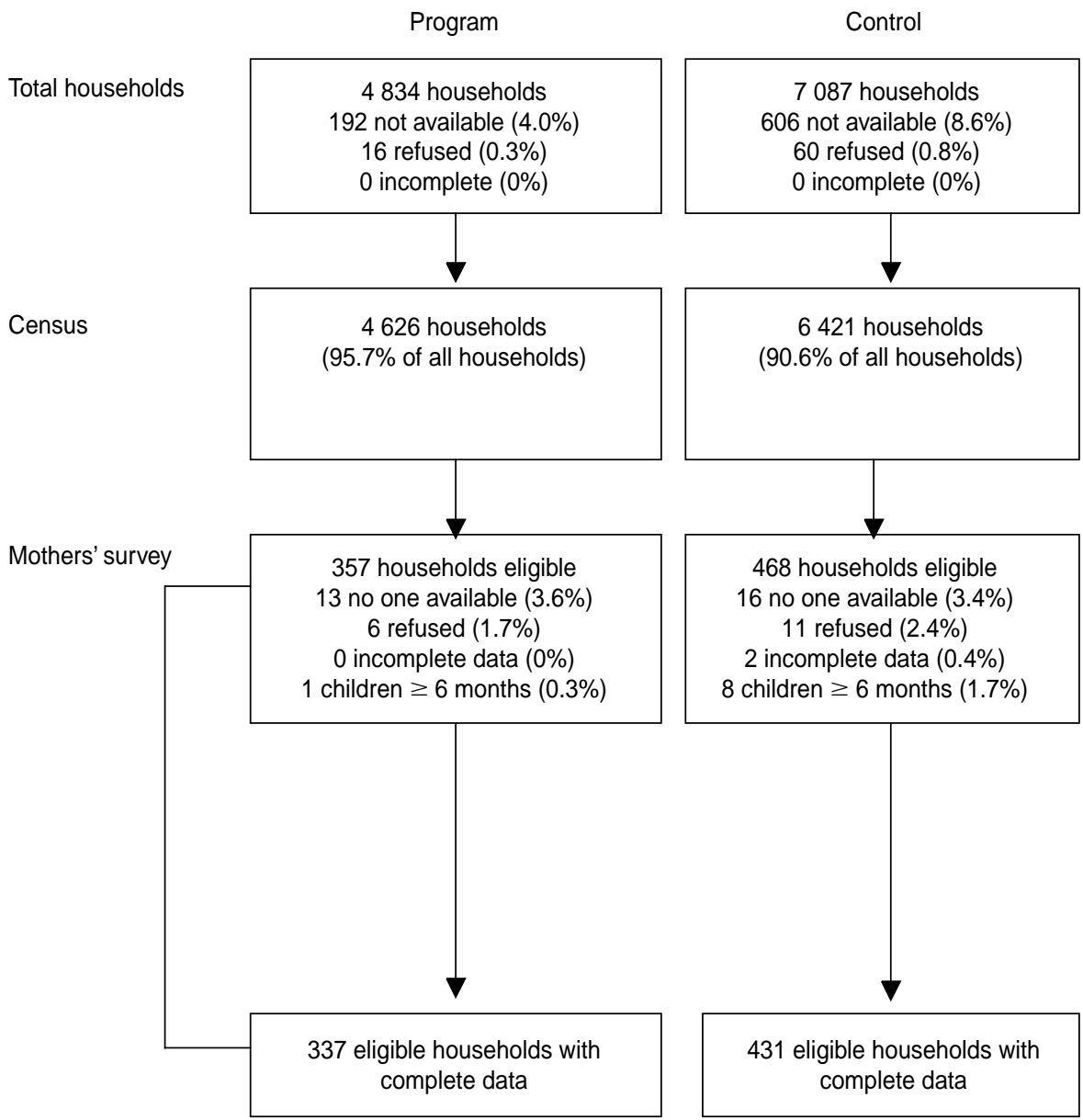

mothers about immediate breast-feeding and about exclusive breast-feeding for the first 6 months and asked pregnant mothers to alert them when their babies were born so that the counselors could provide the new mothers with support and answer their questions. LLLG trained counselors to negotiate improved breast-feeding practices-including exclusive breastfeeding-with mothers during home visits. LLLG also provided more practical training for new counselors. Counselors spent approximately 50\% more time during their 35- to 45-hour training practicing newly acquired facilitation skills with other trainees. LLLG more clearly defined the geo- who have come for prenatal visits and for new mothers who have come for postnatal visits. The health center and its 24-hour maternity ward encourage breast-feeding among mothers who have recently delivered and also coordinate breast-feeding efforts with other government and nongovernmental health organizations, including La Leche League. Health center staff-including volunteer promoters (who are not affiliated with LLLG), doctors, and a director-have been trained in lactation management. In contrast, staff at health centers that serve the second program community and the two control communities have either not received lactation management training or have received only sporadic basic training.

\section{MATERIALS AND METHODS}

This baseline and post-intervention study examined the breast-feeding behaviors of infants less than 6 months of age living in the two program communities (El Limón and La Esperanza) and the two control communities (Guajitos and Ciudad Real II). Methods for this study are described in detail in another article in this issue of this journal (6). Data collection for the follow-up census and survey was carried out between November 2000 and January 2001, one year after the baseline census and survey. Although the baseline survey occurred 10 years after LLLG began training breast-feeding counselors in the program communities, the results of our baseline study (6) suggest that in 1999 there were few differences in exclusive breast-feeding rates between the program communities and the control communities. Lack of earlier impact may be attributable to low levels of exposure to LLLG activities.

Figure 1 outlines the data collection process that was used with the women who were contacted during the follow-up survey. The profile at baseline can be found in the baseline-study article (6). In general, the women in the program and control communities in the follow-up study were similar to each other, except for rates of unavail- 
ability for the census $(8.6 \%$ in the control communities and $4.0 \%$ in the program communities).

The follow-up study asked the women questions on their breast-feeding practices. The definitions of exclusive and predominant breast-feeding that we used were the same as in the baseline study, and they are described elsewhere (7-8). The follow-up mothers' survey was identical to the baseline one, except for several additional questions designed to more accurately identify mothers' contact with La Leche League. Data collection, management, and analysis procedures were the same at follow-up as they had been at baseline (6).

Similar to analyses at baseline, multiple logistic regression analyses identified characteristics-including program exposure-that were associated with early initiation of breast-feeding or exclusive breast-feeding. Variables were kept or dropped from the model based on the Wald statistic, estimated coefficients, and changes in the likelihood ratio test. Interaction terms were included, and all models were checked for overfitting (9).

\section{RESULTS}

The sociodemographic characteristics of mothers residing in the program communities were similar to those for women in the control communities, both at baseline (6) and at follow-up (Table 1). However, at follow-up, mothers residing in control communities had significantly fewer years of formal schooling than did mothers from the program communities. Mothers in control communities were also more likely to have delivered at an $\mathrm{MOH}$ health center or at a private hospital and to have ever been spoken to about breast-feeding. Mothers in program and control communities were far more likely to report receiving advice about breast-feeding at follow-up than at baseline. For example, at baseline, $48 \%$ of mothers in program communities and $41 \%$ of mothers in control communities indicated that someone had spoken to them about breast-feed-

TABLE 1. Characteristics of survey participants in program communities and control communities at follow-up, study of breast-feeding, peri-urban Guatemala City, Guatemala, 1999-2001

\begin{tabular}{|c|c|c|c|}
\hline Characteristic & $\begin{array}{c}\begin{array}{c}\text { Program } \\
\text { communities } \\
(n=337)\end{array} \\
\%\end{array}$ & $\begin{array}{c}\begin{array}{c}\text { Control } \\
\text { communities } \\
(n=431)\end{array} \\
\%\end{array}$ & \\
\hline \multicolumn{4}{|l|}{ Sociodemographic } \\
\hline Child's age (months) & & & 0.575 \\
\hline $0-1$ & 34.4 & 30.9 & \\
\hline $2-3$ & 33.8 & 36.0 & \\
\hline $4-5$ & 31.8 & 33.2 & \\
\hline Child's sex (male) & 49.6 & 49.4 & 0.970 \\
\hline Mother's age (years) & & & 0.128 \\
\hline 15-19 & 22.6 & 16.9 & \\
\hline $20-29$ & 57.6 & 63.3 & \\
\hline$\geq 30$ & 19.9 & 19.7 & \\
\hline Mother's education: & & & 0.004 \\
\hline None & 10.1 & 12.1 & \\
\hline $1-3$ years & 13.7 & 22.5 & \\
\hline $4-6$ years & 40.4 & 31.8 & \\
\hline $7-9$ years & 29.4 & 24.6 & \\
\hline High school or college & 6.5 & 9.1 & \\
\hline Language & & & 0.040 \\
\hline Spanish & 96.4 & 93.0 & \\
\hline Mayan & 3.6 & 7.0 & \\
\hline Water supply & & & $<0.001$ \\
\hline Hose/Purchased by barrel & 9.2 & 2.3 & \\
\hline Public water tap & 5.3 & 3.3 & \\
\hline In house & 85.5 & 94.4 & \\
\hline \multicolumn{4}{|l|}{ Health system } \\
\hline Prenatal care (yes) & 84.3 & 81.2 & 0.266 \\
\hline Child's place of birth & & & $<0.001$ \\
\hline At home & 1.2 & 2.1 & \\
\hline Ministry of Health health center & 38.3 & 42.5 & \\
\hline Ministry of Health hospital & 35.3 & 31.6 & \\
\hline Social Security hospital & 20.2 & 11.6 & \\
\hline Private hospital & 5.0 & 12.3 & \\
\hline \multicolumn{4}{|l|}{ Work and child care } \\
\hline Mother works outside the home & 12.8 & 11.1 & 0.490 \\
\hline Mother takes child to work (yes) & 23.3 & 27.1 & 0.675 \\
\hline \multicolumn{4}{|l|}{ Social support } \\
\hline $\begin{array}{l}\text { Someone had ever spoken to mother } \\
\text { about breast-feeding (yes) }\end{array}$ & 80.7 & 94.9 & $<0.001$ \\
\hline Advised other mothers about & & & \\
\hline breast-feeding (yes) & 59.9 & 61.5 & 0.664 \\
\hline
\end{tabular}

a "Mother takes child to work" includes only those mothers who indicated they worked outside the home.

ing. At follow-up, $81 \%$ of mothers in program communities and $95 \%$ of mothers in control communities said that someone had spoken to them about breast-feeding.

With 22 "active" counselors at baseline, there was 1 breast-feeding counselor for every 10 pregnant women living in the program communities and 1 counselor for every 15 mothers of chil- dren less than 6 months of age. (An "active" counselor was one who had facilitated at least one support group in the last year and who had also submitted monthly reports on level of activity at least three times in the previous year.) At follow-up, one year later, there were 86 active counselors (1 counselor for every 3 pregnant women and 1 for every 4 mothers of 
FIGURE 2. Percent in program communities exposed to La Leche League Guatemala activities, study of breast-feeding, peri-urban Guatemala City, Guatemala, 1999-2001

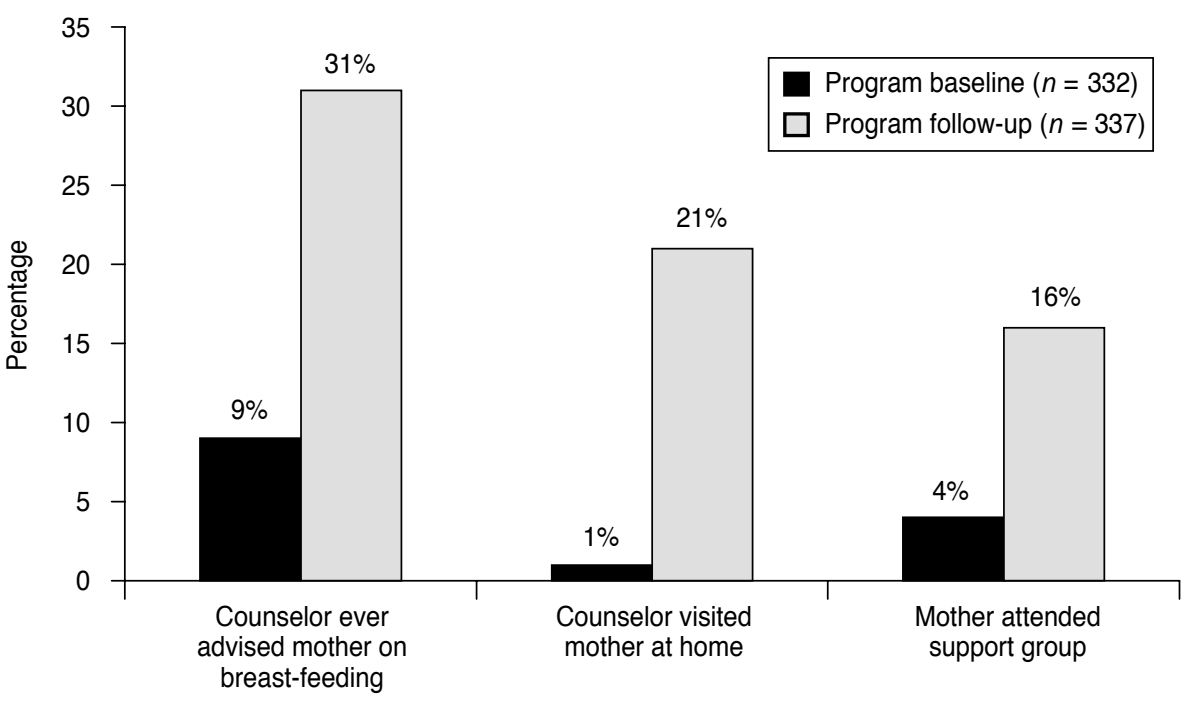

children less than 6 months of age). As expected, there were large increases in the percentage of women in program communities who reported having contact with LLLG (Figure 2).

The results in Table 2 indicate that nearly all the mothers had breast fed at some time; however, at follow-up, only $21 \%$ of mothers in the program communities and $19 \%$ of mothers in the control communities had exclusively breast fed in the preceding 24 hours. The mothers in the program communities were significantly more feed exclusively throughout the previous week. Seventy-one percent of women had used a bottle to feed their infants in the previous 24 hours; $89 \%$ had used a bottle at least once since the child's birth.

Besides breast milk, the two most common substances given in the first month of life were sugar water (given by $41 \%$ of caregivers) and infant formula $(24 \%)$. In the second month of life, 39\% of caregivers provided formula to their infants. Bottle use was widespread. In the 24 hours prior to interview, $66 \%$ of infants less than 1 month of age and $81 \%$ of infants $1-2$ months of age were fed using a bottle. Mothers who had given their babies liquids or foods in addition to breast milk were asked directly why they had done so. Insufficient milk (reported by $36 \%$ of women) and work outside the home $(11 \%)$ were the most frequently cited reasons for not breast-feeding exclusively.

The results presented in Figure 3 indicate that, at follow-up, women within program communities who participated in LLLG breast-feeding promotion and support activities were no more likely than those who did not participate to initiate breast-feeding early. However, Figure 4 suggests that exposure to LLLG activities was associated with exclusive breast-feeding. Of the mothers who had not participated in either home visits or support

TABLE 2. Breast-feeding behaviors by community type, at follow-up, study of breast-feeding, peri-urban Guatemala City, Guatemala, 1999-2001

\begin{tabular}{|c|c|c|c|c|c|c|c|}
\hline \multirow[b]{2}{*}{ Outcome } & \multicolumn{2}{|c|}{$\begin{array}{l}\text { Program } \\
\text { communities } \\
(n=337)\end{array}$} & \multicolumn{2}{|c|}{$\begin{array}{c}\text { Control } \\
\text { communities } \\
(n=431)\end{array}$} & \multirow[b]{2}{*}{$P$ value ${ }^{\mathrm{a}}$} & \multicolumn{2}{|c|}{ Change from baseline } \\
\hline & No. & $\%$ & No. & $\%$ & & Program & Control \\
\hline \multicolumn{8}{|l|}{ Primary } \\
\hline Initiated breast-feeding in first hour & 90 & 27.4 & 84 & 19.6 & 0.011 & $+1.0 \%$ & $+3.0 \%$ \\
\hline Exclusively breast-fed in past 24 hours & 69 & 20.5 & 80 & 18.6 & 0.506 & $+2.1 \%$ & $-3.9 \%$ \\
\hline \multicolumn{8}{|l|}{ Secondary } \\
\hline Not given a bottle in past 24 hours & 99 & 29.4 & 118 & 27.4 & 0.542 & $+2.6 \%$ & $-4.3 \%$ \\
\hline Ever breast-fed & 328 & 97.3 & 429 & 99.5 & 0.011 & $-1.8 \%$ & $+0.8 \%$ \\
\hline $\begin{array}{l}\text { Currently breast-feeding } \\
\text { Predominantly breast-fed in past }\end{array}$ & 310 & 94.5 & 390 & 90.9 & 0.063 & $+4.1 \%$ & $-0.1 \%$ \\
\hline 24 hours & 93 & 27.6 & 122 & 28.3 & 0.828 & $+17.7 \%$ & $+15.3 \%$ \\
\hline
\end{tabular}

a $P$ values compare program and control communities at follow-up. 
FIGURE 3. Percent initiating breast-feeding in first hour, by exposure to La Leche League Guatemala activities (program communities only), study of breast-feeding, peri-urban Guatemala City, Guatemala, 1999-2001

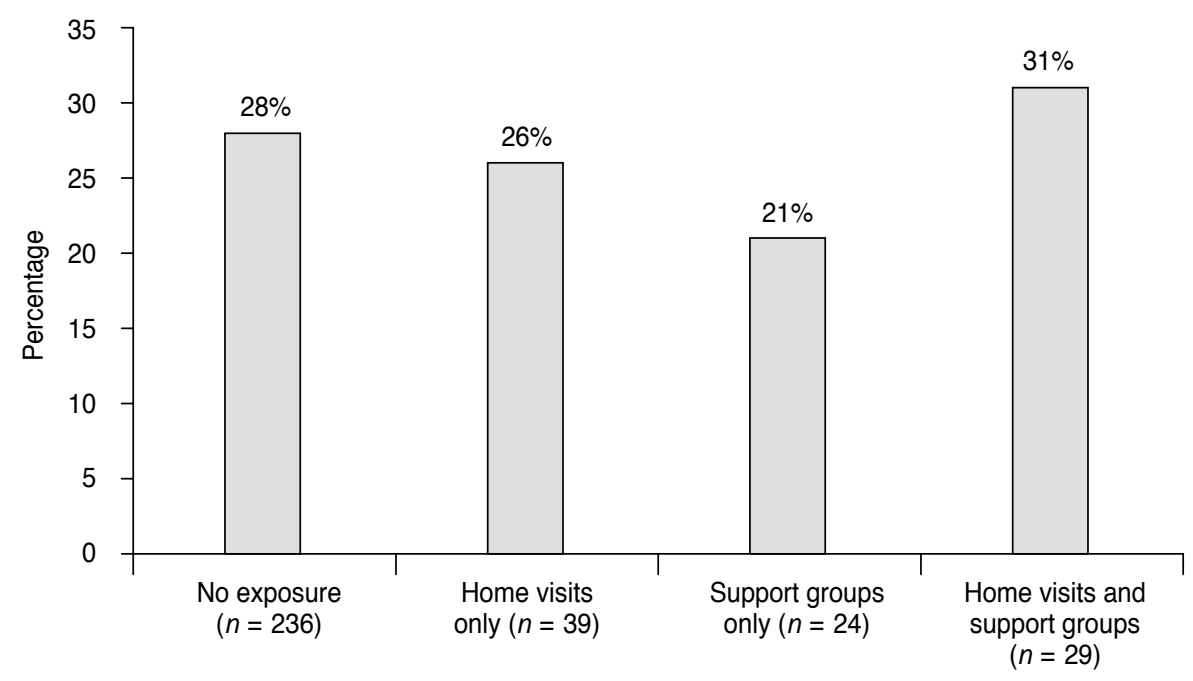

groups, $14 \%$ of them had exclusively breast fed in the previous 24 hours, compared with $45 \%$ of women who had participated in both types of activities and $42 \%$ of women who had participated in support groups only. Additionally, women at follow-up who were exposed to LLLG interventions were more likely than women exposed at baseline to exclusively breast-feed. For example, at baseline, $13 \%$ of mothers who had ever been advised by a counselor exclusively breast fed, com-

FIGURE 4. Percent exclusively breast-feeding, by exposure to La Leche League Guatemala activities (program communities only), study of breast-feeding, peri-urban Guatemala City, Guatemala, 1999-2001

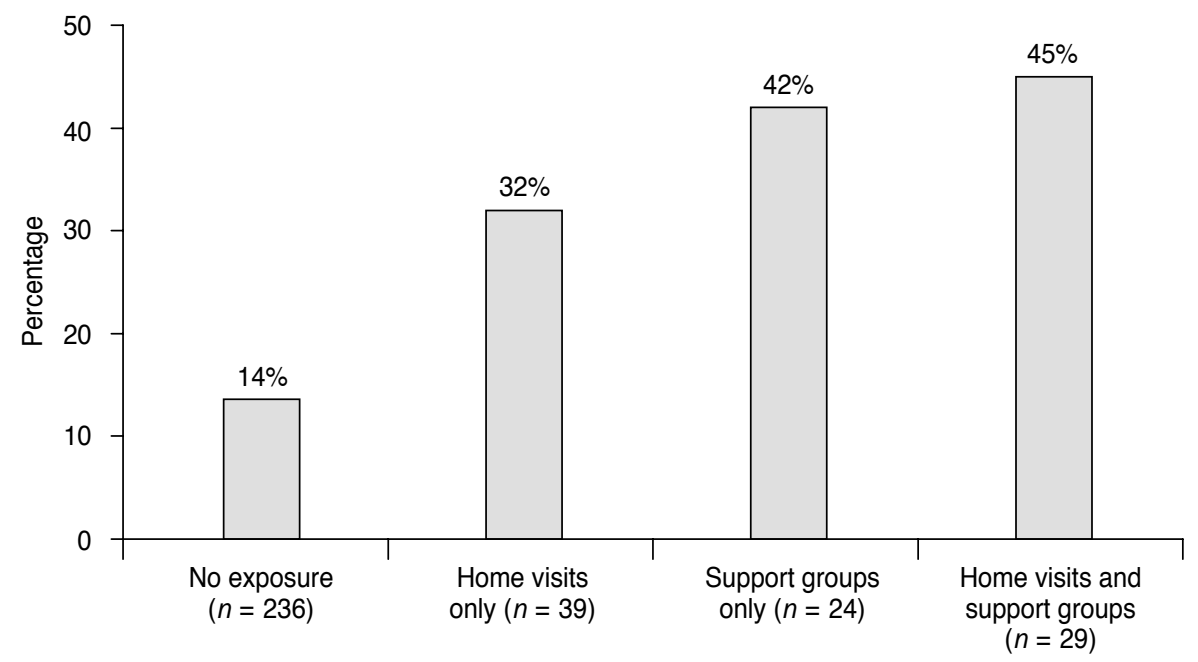

selors to initiate breast-feeding in the first hour; however, they were more likely to exclusively breast feed ( $28 \%$ vs. $17 \%, P=0.004)$. If women had heard about breast-feeding from health personnel, mothers, or their mothers-inlaw, they were less likely to initiate breast-feeding early than were women who had not heard about breast-feeding from these sources. For example, $20 \%$ of the mothers who spoke to health care personnel initiated breast-feeding in the first hour, as compared to $27 \%$ of mothers who had not discussed breast-feeding with health care personnel $(P=0.05)$. Hearing about breastfeeding from health care personnel and mothers-in-law was not associated with exclusive breast-feeding.

Multiple logistic regression was used to summarize the significant independent factors associated with early initiation and exclusive breastfeeding at baseline and at follow-up, accounting for confounding factors. At baseline and at follow-up, place of delivery was significantly associated with initiation of breast-feeding. At baseline, women who delivered at home and at Ministry of Health $(\mathrm{MOH})$ health centers were significantly more likely than women delivering in a private hospital to initiate breast-feeding in the first hour of life (odds ratio (OR) for at-home delivery $=4.1$, and $95 \%$ confidence interval (CI): 1.2-13.3; OR for $\mathrm{MOH}$ health centers $=4.9$, and $95 \%$ CI: 1.6-15.0). At follow-up, mothers who delivered at an $\mathrm{MOH}$ health center $(\mathrm{OR}=5.4,95 \% \mathrm{CI}: 3.0-9.7)$ or at an $\mathrm{MOH}$ hospital $(\mathrm{OR}=3.7,95 \%$ CI: 2.1-6.5) were more likely than mothers delivering at a private hospital to initiate breast-feeding in the first hour. At baseline and follow-up, no other place of delivery was significantly associated with early initiation of breastfeeding. At follow-up, mothers residing in program communities were more likely to initiate breast-feeding early $(\mathrm{OR}=1.6,95 \% \mathrm{CI}: 1.1-2.3)$.

The factors associated with exclusive breast-feeding were also similar at baseline and follow-up. At follow-up, the most prominent risk factors for failure to exclusively breast-feed were mother's work outside the home $(\mathrm{OR}=$ 
5.3, 95\% CI: 1.9-15.3) and lack of exposure to LLLG activities, after controlling for the child's age and sex and the mother's ethnicity. Mothers who received a home visit by a breast-feeding counselor and participated in support groups were 5.4 times as likely (95\% CI: 2.3-12.6) as were mothers with no exposure to LLLG activities to exclusively breast-feed. Mothers who participated in support groups only were 4.8 times as likely to exclusively breast-feed (95\% CI: 1.9-11.8) as were mothers who did not participate in the groups. Similarly, mothers who participated in home visits only were 3.4 times as likely to exclusively breastfeed (95\% CI: 1.6-7.2) as were mothers who did not participate in home visits.

Multiple logistic regression was also used to determine whether the change in breast-feeding behaviors from baseline to follow-up in the program communities was significantly different from the change in breast-feeding behaviors in the control communities. The change in early initiation of breastfeeding in the program communities (as measured by the odds ratio at follow-up divided by the odds ratio at baseline, or the ratio of odds ratios (ROR)) was not significantly different from the change in the control communities (ROR $=0.9$; 95\% CI: 0.5-1.4). Likewise, the change in exclusive breast-feeding in the program and control communities was not significantly different $(\mathrm{ROR}=1.5 ; 95 \% \mathrm{CI}$ : 0.9-2.4).

\section{DISCUSSION}

This research contributes to a growing body of literature on the impact of community-based breast-feeding promotion and support. Findings from this study suggest that while periurban Guatemala City provides a culture that is generally supportive of breast-feeding, breast-feeding behaviors were far from optimal: $80 \%$ of mothers of children less than 6 months of age did not exclusively breast-feed in the previous 24 hours. Results also suggest that, over the course of a oneyear time period, the independent breast-feeding promotion and support activities enacted by LLLG did not impact exclusive breast-feeding practices at the community level. However, only $31 \%$ of mothers participated in LLLG programs at any level. Even so, mothers who directly participated in $\mathrm{La}$ Leche League activities were more likely to practice exclusive breast-feeding than mothers who did not participate. Additionally, results from this study suggest LLLG was more successful at convincing women to exclusively breast-feed by the end of the follow-up period than had been true at baseline.

Limitations of this intervention study include higher rates of absenteeism for the census in control communities as well as retrospective data collection, making it difficult to obtain such information as whether and how expectant mothers intended to breastfeed. Additionally, the follow-up assessment occurred one year after the intervention. It is possible that the intervention had a greater impact on breast-feeding practices; however, the long-term impact of the program was not measured.

Self-selection might explain why mothers in program communities who participated in LLLG activities were more likely than mothers in those communities who did not participate to initiate breast-feeding in the first hour of life and to exclusively breast feed. While it is not possible to rule out selfselection as an explanation for positive results, separate analyses conducted by the co-authors of this study provide no evidence of self-selection in periurban Guatemala City. There were significant differences between mothers who participated in LLLG activities (participants) and mothers who had no exposure to LLLG activities or had heard of LLLG activities but chose not to participate (nonparticipants). For example, mothers who participated in LLLG activities were significantly more likely than nonparticipants to have older infants (4-5 months of age), to have more formal schooling, and to be of Spanish heritage rather than Mayan heritage. Since these factors are often associated with suboptimal breast-feeding practices (10), this suggests that women who participated in
LLLG activities may have been at greater risk of not exclusively breastfeeding.

In developing countries, only a few community-based studies have been carried out to examine the relationship between breast-feeding promotion and support and optimal breast-feeding practices. One study, carried out by Freedom from Hunger in Ghana over a three-year period (11), suggests that "Credit with Education" (small-scale loans and group education about health and nutrition, including breastfeeding) was positively associated with several breast-feeding behaviors. Notably, program participants were significantly more likely to give colostrum than were mothers in control communities and mothers in program communities who did not participate in Credit with Education. Program participants were also more likely to delay the introduction of water and to never use a bottle. There were no significant differences between nonparticipants and controls.

A randomized controlled trial in Mexico (12) demonstrated large increases in rates of exclusive breastfeeding using paid peer counselors. Equally impressive results have recently been obtained in another randomized controlled trial using paid peer counselors in urban Bangladesh (13). In both Mexico and Bangladesh, all the women in the program communities who agreed to participate in the study received breast-feeding promotion and support. Consequently, it is not possible to determine whether women in the program communities in those two countries who did not participate in the programs improved breast-feeding practices.

Studies carried out among low-income women in more-industrialized nations suggest that the use of peer counselors can positively affect initiation of breast-feeding as well as the prevalence of breast-feeding shortly postpartum. The evidence about the long-term impact of peer counseling on prevalence of breast-feeding is mixed (14-16). In an exhaustive review of the literature, Fairbank and colleagues (16) have noted that peer 
support programs delivered in the antenatal and postnatal periods have been associated with increased initiation and duration of breast-feeding. A similar review in developing countries (3) suggests that peer counseling and social support are generally positively associated with initiation of breastfeeding, giving colostrum, and exclusive breast-feeding.

Social support for breast-feeding may be emotional or informational, or it may facilitate other forms of support, including clinical support for breast-feeding problems. It is difficult, however, to evaluate the various types of support mothers receive. This study of Guatemala assesses general social support for breast-feeding, including whether someone spoke to mothers about breast-feeding, who spoke with them, and the mothers' participation in LLLG activities. Additional quantitative and qualitative research is needed to identify the kinds of support women receive and to determine whether certain types of support are more closely linked to optimal breastfeeding behaviors.

At least two important questions emerge from this study. First, why were there large increases from baseline to follow-up in the percent of women in control communities who indicated someone had spoken to them about breast-feeding? Second, why is there a lack of communitywide impact of mother-to-mother support on optimal breast-feeding practices?

Some answers to these questions are suggested by findings from a yearlong qualitative study that was carried out as part of this research. The goal of that qualitative study was to document potential influences on breastfeeding knowledge, attitudes, and practices in both program and control communities. Results point to only one external factor that might have influenced exposure to breast-feeding messages. Between 1998 and 2001, 869 Cuban physicians came to Guatemala to open health posts, strengthen hospitals, and address the health care needs of individuals. Some physicians worked intensively in one of the control communities but not in the other three communities that were included in this study. Much of their work was community-based promotion of family health, including an active focus on breast-feeding. Anecdotal evidence suggests that mothers readily received and listened to the advice of the Cuban doctors.

Several factors might explain the lack of impact of mother-to-mother support on exclusive breast-feeding practices at the community level. While LLLG had been active in the program communities for nearly a decade prior to the baseline study, intensive efforts to reach large numbers of women only began in 1999. Because recruitment and training occurred on a rolling basis, newly trained breast-feeding counselors had, on average, less than a half year to carry out home visits and to facilitate support groups. Additionally, the frequency with which volunteer breast-feeding counselors conducted home visits and support groups varied from counselor to counselor (all counselors were encouraged to hold at least one support group per month). Consequently, women may not have received sufficient support throughout pregnancy and at critical junctures in the first 6 months postpartum, when important decisions about breast-feeding are made. Studies in Mexico (12) and in Bangladesh (13) point to the importance of early and repeated contact with peer counselors. Literature reviews by Fairbank and colleagues (16) and by Green (3) have noted the effectiveness of packages of interventions, including peer support, women's groups, mass media campaigns, national policy changes, changes in hospital practices, counseling and health education, and integration of community interventions with the formal health system. Historically, most of La Leche League's efforts in Guatemala have focused on the single intervention of peer support, delivered through home visits, counseling and referral, and support groups.

This study does not provide evidence that La Leche League was able to achieve population-level changes in breast-feeding practices after one year of program implementation. Even so, breast-feeding promotion and support appear to improve breast-feeding practices among those who have direct contact with La Leche League. Additionally, participation in League activities likely benefits women in ways not measured by this study.

How might the community-level impact of mother-to-mother support activities be increased? Other research (12) suggests that community-based initiatives to promote and support breast-feeding should be geared toward women during pregnancy, when decisions about infant-feeding are made. In addition to improved targeting of women, behavior change approaches may need to be more explicit by discouraging the use of sugar water and infant formula, especially in the first few months of life; by emphasizing the importance of exclusive breast-feeding; and by providing mothers with specific options for exclusively breastfeeding their children. Furthermore, long-term community-based interventions will most likely need to be carried out in partnership with existing health care systems to ensure communitywide improvements in breast-feeding practices.

Acknowledgements. The authors gratefully acknowledge the interviewers who participated in data collection, as well as the input and review provided by Kathy Baker, Rebecca Magalhaes, and Bruce Newman. The authors also wish to express heartfelt posthumous thanks to Lydia de León, who managed the field portion of the study. This research was funded by LINKAGES (Breastfeeding, LAM and Related Complementary Feeding, and Maternal Nutrition Program). LINKAGES is supported by the GH/HIDN, United States Agency for International Development, under Cooperative Agreement No. HRN-A-00-97-00007-00, and managed by the Academy for Educational Development. The opinions expressed herein are those of the authors and do not necessarily reflect the views of the U.S. Agency for International Development nor The LINKAGES Project. 


\section{REFERENCES}

1. Sanghvi T. Improving the cost-effectiveness of breastfeeding promotion in maternity services: summary of the USAID/LAC HNS study in Latin America (1992-1995). San Diego, California, United States of America: Wellstart International; 1995.

2. Popkin B, Canahuati J, Bailey P, O'Gara C. An evaluation of a national breast-feeding promotion programme in Honduras. J Biosoc Sci 1991;23:5-21.

3. Green C. Improving breastfeeding behaviors: evidence from two decades of intervention research. Washington, D.C.: The LINKAGES Project, Academy for Educational Development; 1999.

4. Sikorski J, Renfrew MJ, Pindoria S, Wade A. Support for breastfeeding mothers (Cochrane Review). In: The Cochrane Library, Issue 1, 2002. Oxford: Update Software; 2002.

5. Green CP. Mother support groups: a review of experience in developing countries. Arlington, Virginia, United States: Basic Support for Institutionalizing Child Survival (BASICS) Project; 1998.

6. Dearden K, Altaye M, de Maza I, de Oliva M, Stone-Jimenez M, Morrow AL, Burkhalter BR. Determinants of optimal breast-feeding in peri-urban Guatemala City, Guatemala. Rev Panam Salud Publica 2002;12(3):185-192.

7. Lung'aho M, Huffman S, Labbok M, Sommerfelt E, Baker J. Tool kit for monitoring and evaluating breastfeeding practices and programs. Washington D.C.: Wellstart International; 1996.

8. World Health Organization. Indicators for assessing breastfeeding practices. Geneva: WHO; 1991.

9. Hosmer DW, Lemeshow S. Applied logistic regression. New York: John Wiley \& Sons, Inc.; 2000.

10. Haggerty P, Rutstein S. Breastfeeding and complementary infant feeding, and the postpartum effects of breastfeeding. Calverton, Maryland, United States: Macro International; 1999. (Demographic and Health Surveys Comparative Studies No. 30).

11. MkNelly B, Dunford C. Impact of Credit with Education on mothers' and their young children's nutrition: Lower Pra Rural Bank Credit with Education program in Ghana. Davis, California, United States: Freedom from Hunger; 1998.

12. Morrow A, Guerrero M, Shults J, Calva J, Lutter C, Bravo J, et al. Efficacy of home-based peer counselling to promote exclusive breastfeeding: a randomised controlled trial. Lancet 1999;353:1226-1231.

13. Haider R, Ashworth A, Kabir I, Huttly S. Effect of community-based peer counsellors on exclusive breastfeeding practices in Dhaka, Bangladesh: a randomised controlled trial. Lancet 2000;356:1643-1647.

14. Schafer E, Vogel MK, Viegas S, Hausafus C. Volunteer peer counselors increase breastfeeding duration among rural low-income women. Birth 1998;25(2):101-106.

15. Long DG, Funk-Archuleta MA, Geiger CJ, Mozar AJ, Heins JN. Peer counselor program increases breastfeeding rates in Utah Native American WIC population. J Hum Lact 1995; 11(4):279-284.

16. Fairbank L, O'Meara S, Renfrew MJ, Woolridge $M$, Sowden AJ, Lister-Sharp D. A systematic review to evaluate the effectiveness of interventions to promote the initiation of breastfeeding. Health Technol Assess 2000;4 (25):1-171.

Manuscript received 26 June 2002. Accepted for publication on 15 July 2002.

RESUMEN Objetivos. Evaluar el impacto de un programa de apoyo entre las madres sobre el inicio temprano de la amamantación y la lactancia exclusivamente materna. El programa fue llevado a cabo por la organización "Liga la Leche" de Guatemala en la zona periurbana de la capital del país.

Impacto del apoyo entre las madres sobre la amamantación óptima: ensayo controlado de intervención comunitaria en la zona periurbana de la Ciudad de Guatemala

Métodos. Tras un censo de población para identificar a todas las madres de cuatro comunidades con hijos menores de 6 meses, se les realizó una encuesta sobre sus prácticas de amamantación. Un año más tarde, entre noviembre de 2000 y enero de 2001, se repitieron el censo y la encuesta y se compararon las dos comunidades donde se realizó el programa de intervención (comunidades $\mathrm{P}$ ) con las dos comunidades de control (comunidades C).

Resultados. En la segunda encuesta, 31\% de las madres de las comunidades P dijeron haber recibido asesoramiento sobre la lactancia materna, 21\% dijeron haber recibido una visita en su domicilio y $16 \%$ dijeron asistir a las reuniones de un grupo de apoyo. Las tasas de comienzo temprano de la lactancia materna fueron mayores en las comunidades $\mathrm{P}$ que en las comunidades $\mathrm{C}$, pero esto ocurrió tanto antes como después de la realización del programa; además, los cambios a lo largo del tiempo en la iniciación temprana de la lactancia materna no presentaron diferencias significativas entre ambos tipos de comunidades. Las tasas de lactancia exclusivamente materna fueron similares en las comunidades $\mathrm{P}$ y $\mathrm{C}$ y no cambiaron significativamente a lo largo del tiempo. No obstante, entre las madres de las comunidades $\mathrm{P}$ que recibieron visitas a domicilio y asistieron a las reuniones de los grupos de apoyo, la tasa de lactancia exclusivamente materna fue de $45 \%$, en comparación con $14 \%$ en las mujeres de las mismas comunidades que no participaron en estas actividades. Además, la probabilidad de que la lactancia fuera exclusivamente materna fue mayor en las mujeres que participaron en actividades de apoyo entre madres durante el año posterior al censo y encuesta basales que en las que participaron en dichas actividades antes del mencionado período. Esto indica que la eficacia de las actividades del programa aumentó con el tiempo.

Conclusiones. Este estudio no aporta pruebas de que la intervención de la "Liga la Leche" haya tenido impacto en la población un año después de su puesta en práctica. Para conseguir mejorar las tasas de lactancia exclusivamente materna en la zona periurbana de Guatemala podrían ser necesarias intervenciones comunitarias a largo plazo, en colaboración con los sistemas de asistencia sanitaria ya existentes. 